\title{
The Canadian National EMS Research Agenda: Impact and Feasibility of Implementation of Previously Generated Recommendations
}

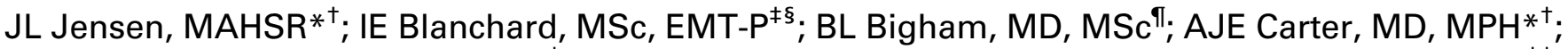 \\ $\mathrm{R}$ Brown, $\mathrm{MPH}(\mathrm{c}), \mathrm{BSc}(\mathrm{Hons})^{*+}$; D Socha, MA, BSc**; LH Brown, PhD, MPH\&TM ${ }^{\dagger+}$; \\ $\mathrm{AH}$ Travers, MD, MSc ${ }^{*}$; $\mathrm{AM}$ Craig, MScPI, BA(Hons) ${ }^{\ddagger \ddagger \S \S}$; LJ Morrison, MD, MSc ${ }^{\text {Tा }}$
}

\section{ABSTRACT}

Background: A recent mixed-methods study on the state of emergency medical services (EMS) research in Canada led to the generation of nineteen actionable recommendations. As part of the dissemination plan, a survey was distributed to EMS stakeholders to determine the anticipated impact and feasibility of implementing these recommendations in Canadian systems.

Methods: An online survey explored both the implementation impact and feasibility for each recommendation using a fivepoint scale. The sample consisted of participants from the Canadian National EMS Research Agenda study (published in 2013) and additional EMS research stakeholders identified through snowball sampling. Responses were analysed descriptively using median and plotted on a matrix. Participants reported any planned or ongoing initiatives related to the recommendations, and required or anticipated resources. Free text responses were analysed with simple content analysis, collated by recommendation.

Results: The survey was sent to 131 people, 94 (71.8\%) of whom responded: 30 EMS managers/regulators (31.9\%), 22 researchers $(23.4 \%), 15$ physicians $(16.0 \%), 13$ educators $(13.8 \%)$, and 5 EMS providers (5.3\%). Two recommendations $(11 \%)$ had a median impact score of 4 (of 5) and feasibility score of 4 (of 5). Eight recommendations (42\%) had an impact score of 5 , with a feasibility score of 3 . Nine recommendations $(47 \%)$ had an impact score of 4 and a feasibility score of 3.

Conclusions: For most recommendations, participants scored the anticipated impact higher than the feasibility to implement. Ongoing or planned initiatives exist pertaining to all recommendations except one. All of the recommendations will require additional resources to implement.

\section{RÉSUMÉ}

Contexte: Une étude récente, reposant sur différentes méthodes et portant sur l'état de la recherche sur les services médicaux d'urgence (SMU) au Canada a mené à l'élaboration de 19 recommandations susceptibles de mise en application. Dans le cadre du plan de diffusion, un questionnaire d'enquête a été envoyé aux différents intervenants dans les SMU afin de déterminer la faisabilité et l'incidence prévisible de la mise en œuvre de ces recommandations dans des systèmes de prestation de soins au Canada.

Méthode: L'enquête en ligne portait tant sur la faisabilité que sur l'incidence de la mise en œuvre de chacune des recommandations, sur une échelle à 5 points. L'échantillon se composait de participants à l'étude menée dans le cadre du projet Canadian National SMU Research Agenda (publiée en 2013) ainsi que d'autres intervenants en recherche sur les SMU, trouvés à la suite d'un sondage en boule de neige. Les réponses ont fait l'objet d'une analyse descriptive à l'aide de valeurs médianes et de lignes tracées sur une grille. Les participants ont fait état d'initiatives en cours ou à venir, liées aux recommandations, ainsi que des ressources nécessaires ou prévues. Les réponses formulées en texte libre ont été soumises à une simple analyse de contenu, et groupées selon les recommandations.

Résultats: Le questionnaire a été envoyé à 131 personnes; sur ce nombre, 94 y ont répondu (71,8\%): 30 directeurs de SMU ou chargés de la réglementation en la matière $(31,9 \%)$, 22 chercheurs $(23,4 \%), 15$ médecins $(16,0 \%), 13$ éducateurs $(13,8 \%)$ et 5 fournisseurs de SMU (5,3\%). Deux recommandations (11\%) ont obtenu un score médian d'incidence de 4 (sur 5) et un score médian de faisabilité de 4 (sur 5); 8 recommandations ( $42 \%$ ), un score d'incidence de 5 et un score de faisabilité de 3; 9 recommandations ( $47 \%$ ), un score d'incidence de 4 et un score de faipbsabilité de 3 .

From the *Emergency Health Services, Dartmouth, NS; †Division of Emergency Medical Services, Dalhousie University, Halifax, NS; $¥$ Alberta Health Services Emergency Medical Services, Edmonton, AB; §Department of Community Health Sciences, Faculty of Medicine, University of Calgary, Calgary, AB; \Faculty of Medicine, McMaster University, Hamilton, ON; **Hastings-Quinte Paramedic Services, Belleville, ON; $\uparrow \dagger J a m e s$ Cook University, Townsville, Australia; $\ddagger$ Toronto Emergency Medical Services, Toronto, ON; §§American Medical Response, San Diego, CA, USA; and ITRescu, Keenan Research Centre, Li Ka Shing Knowledge Institute, St. Michael's Hospital, University of Toronto, Toronto, ON.

Correspondence to: R. Brown, 1500 George Street, Sydney, Nova Scotia, Canada, B1P 1P3; Email: ryan.brown@emci.ca 
Conclusions: Les participants ont accordé, dans la plupart des recommandations, un score plus élevé d'incidence prévisible qu'un score de faisabilité de mise en œuvre. Des initiatives en cours ou à venir ont aussi été relevées en lien avec toutes les recommandations, à l'exception d'une seule. Enfin, des ressources supplémentaires sont à prévoir pour la mise en œuvre de toutes les recommandations.

Keywords: agenda, emergency medical services, research, implementation, stakeholders

\section{BACKGROUND}

Research agendas provide a roadmap and strategic direction to improve the quantity and quality of research production and application, and can identify areas in most need of research attention. Several countries have developed emergency medical services (EMS) research agendas, including the United States, Ireland, Australia, and, most recently, Canada. ${ }^{1-5}$ Research agendas also exist for specific topics within EMS, including pediatrics and community paramedicine. ${ }^{6,7}$ Nineteen recommendations for the future of Canadian EMS research were generated in the Canadian National EMS Research Agenda published in 2013 (Figure 1). ${ }^{4}$ Some of these Canadian recommendations were similar to those from other locations, including the development of research careers in EMS and the need for further funding. ${ }^{8}$ In addition, some are known to have now been implemented, such as the National Registry of Emergency Medical Technicians Research Fellowship in the United States.

While developing research agendas can be important, what is more important are the changes that result from such an initiative, and the effect of those changes. The U.S. EMS Research Agenda published an implementation plan putting forth eight implementationfocused recommendations. ${ }^{9,10}$ However, outcomes of agenda recommendations have not been reported from any of these. The impact of EMS research agendas on improving the quantity or quality of research performed or applied is unknown.

As described by Graham, knowledge must be both created and then subsequently applied. ${ }^{11}$ Part of effectively applying the results of research to a given setting is identifying which knowledge is most important (i.e., adapting knowledge to the context) and identifying barriers to its use, or what is required to put it to action. ${ }^{11}$ Although Canadian National EMS Research Agenda generated nineteen recommendations for improving EMS research conducted and used in Canada, it, too, requires a focused and purposeful implementation strategy for real change to occur.
The purpose of this implementation study was to determine the anticipated impact and feasibility of the Canadian EMS Research Agenda recommendations. The specific objectives are to develop an actionable implementation strategy for the Canadian EMS Research Agenda through: 1) ranking each of the nineteen recommendations on its a) potential impact (i.e., could it make a difference?) and b) feasibility of implementation, and 2) identifying and cataloguing a) existing or planned initiatives from across Canada that relate to each recommendation and b) the resources required for implementation.

\section{METHODS}

This study was a cross-sectional electronic online survey of EMS research stakeholders in Canada. The survey was open from December 1 to December 20, 2012, and was approved by the Capital District Health Authority Research Ethics Board in Halifax.

The sample included past participants from the Canadian National EMS Research Agenda study, ${ }^{12}$ as well as other EMS research stakeholders identified through investigator knowledge and snowball sampling of the participant group. ${ }^{13}$ Sampling was purposeful, from locations across the country and in a variety of EMS system types, to ensure a mix of participants who work in various clinical and research roles in EMS. Participation was voluntary, and consent was implied by partial or full completion and submission of the online survey. The survey was delivered using an electronic survey tool (Opinio version 6.5.2, Objectplanet, Oslo, Norway). The survey was sent via email to the email address identified for each participant during snowball sampling. Reminder emails were sent out every 5 days to nonrespondents for a maximum total of three times.

Participants were asked to score each of the nineteen recommendations using a five-point Likert scale regarding whether the recommendation was anticipated to make a difference (impact score) and the anticipated 


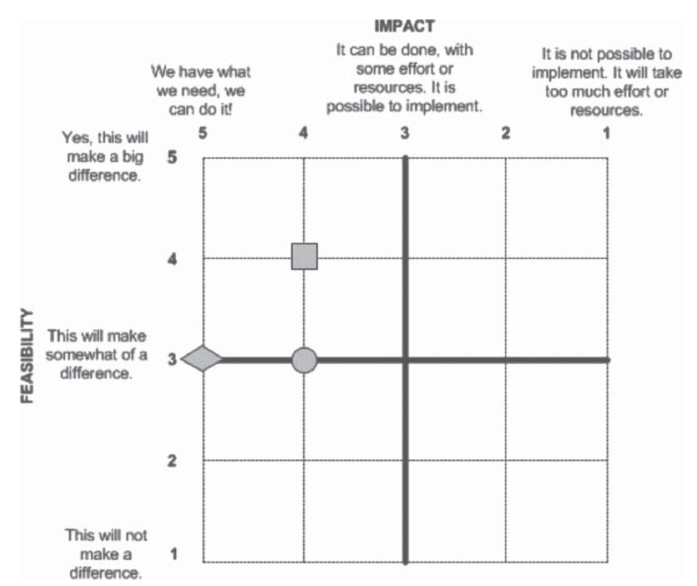

\begin{tabular}{|c|c|c|}
\hline $\begin{array}{c}\text { Matrix } \\
\text { position }\end{array}$ & $\begin{array}{l}\text { Recommendation } \\
\text { number }\end{array}$ & Recommendation \\
\hline \multirow[t]{2}{*}{$\square$} & 8 & $\begin{array}{l}\text { Information should be purposefully disseminated to EMS } \\
\text { providers about EMS research activities occurring in Canada. }\end{array}$ \\
\hline & 16 & $\begin{array}{l}\text { Highlight EMS research in special issues or sections of the } \\
\text { Canadian Journal of Emergency Medicine. }\end{array}$ \\
\hline \multirow[t]{9}{*}{ O } & 1 & $\begin{array}{l}\text { Strategically market the importance of EMS research to other } \\
\text { agencies, health groups, and the public. }\end{array}$ \\
\hline & 7 & $\begin{array}{l}\text { Provide scholarships for EMS providers, managers, and } \\
\text { physicians to take research-based graduate degrees. }\end{array}$ \\
\hline & 9 & $\begin{array}{l}\text { Increase multidisciplinary strategic partnerships to broaden the } \\
\text { topics studied in EMS research. }\end{array}$ \\
\hline & 10 & $\begin{array}{l}\text { Engage EMS providers and managers early in the research } \\
\text { process and include them on study teams. }\end{array}$ \\
\hline & 12 & $\begin{array}{l}\text { EMS researchers must undertake comprehensive knowledge } \\
\text { translation initiatives, including delivering research results to } \\
\text { EMS providers and administrators. }\end{array}$ \\
\hline & 14 & $\begin{array}{l}\text { The network of Canadians interested in EMS research should be } \\
\text { formalized, possibly as a national EMS research organization or } \\
\text { conferences. }\end{array}$ \\
\hline & 15 & $\begin{array}{l}\text { EMS researchers and administrators should better inform } \\
\text { research ethics boards about the nature of EMS research and } \\
\text { request EMS experts to participate on review committees. }\end{array}$ \\
\hline & 18 & $\begin{array}{l}\text { Create a national EMS data dictionary of operational and clinical } \\
\text { terms. }\end{array}$ \\
\hline & 19 & $\begin{array}{l}\text { The EMS Research Agenda needs to be viewed as an ongoing } \\
\text { project. An implementation, evaluation, and renewal plan should } \\
\text { be designed, and this process should in clude mapping gaps in } \\
\text { EMS research. }\end{array}$ \\
\hline \multirow[t]{8}{*}{ 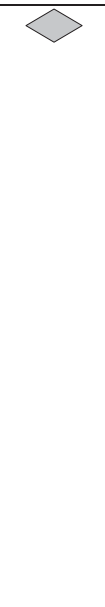 } & 2 & $\begin{array}{l}\text { Strengthen research partnerships between EMS academic centers, } \\
\text { systems, regulators, educators, and national associations. }\end{array}$ \\
\hline & 3 & $\begin{array}{l}\text { Increase funding opportunities for EMS research infrastructure } \\
\text { and studies. }\end{array}$ \\
\hline & 4 & $\begin{array}{l}\text { Universities should consider EMS providers with graduate } \\
\text { training for academic appointments, so they can engage in } \\
\text { academic EMS research. }\end{array}$ \\
\hline & 5 & $\begin{array}{l}\text { Create opportunities for EMS providers to work in research } \\
\text { positions. Review collective agreements, if necessary. }\end{array}$ \\
\hline & 6 & $\begin{array}{l}\text { Integrate research literacy and research competencies into EMS } \\
\text { providers', managers', and EMS physicians' foundational and } \\
\text { continuing education. }\end{array}$ \\
\hline & 11 & $\begin{array}{l}\text { EMS systems administrators should budget for research projects } \\
\text { during annual strategic planning. }\end{array}$ \\
\hline & 13 & $\begin{array}{l}\text { Evidence-based decision-making should be encouraged in EMS } \\
\text { systems. If evidence is lacking, further research should be } \\
\text { undertaken. }\end{array}$ \\
\hline & 17 & EMS data should be linked with hospital and other datasets. \\
\hline
\end{tabular}

Figure 1. Recommendations matrix: impact $X$ feasibility. 
ease or difficulty of implementation (feasibility score). Results were analysed descriptively and, where appli cable, reported as medians with interquartile ranges (IQR). Recommendations were also plotted on a matrix of impact score by feasibility score.

Participants were also asked to provide free-text responses describing any planned or ongoing initiatives that related to the recommendations, and asked to report on the resources that were required, or the resources they anticipate would be required to implement each recommendation. Two investigators (JJ and $\mathrm{RB})$ reviewed any reported initiatives and resources to align them with the most appropriate recommendation. For each recommendation, the number of unique ongoing or planned initiatives and required resources was reported descriptively. The survey can be found in Appendix A.

\section{RESULTS}

\section{Participants}

Of 131 people invited to participate, 94 (71.8\%) responded. Participants reported a median of 19.0 years of experience in EMS (IQR 12.5-25.0). The participant group represented a mixture of roles across a spectrum of organization types and provinces and territories. Study participant characteristics are provided in Table 1.

\section{Impact and feasibility of the recommendations}

The median survey responses for the anticipated impact and feasibility of each recommendation are plotted on a matrix (see Figure 1) and listed in a tabular format (Table 2). The median scores for the impact and feasibility of each recommendation are plotted on a matrix in Figure 1 and listed in a tabular format in Table 2. Eight recommendations had a median impact of 5 , with a median feasibility of 3 , indicating that survey participants felt that these recommendations would make a big difference, and that they could be accomplished with some additional effort or resources. These recommendations were the following:

- Strengthen research partnerships between EMS academic centers, systems, regulators, educators, and national associations (\#2).

- Increase funding opportunities for EMS research infrastructure and studies (\#3).
Table 1. Study participant characteristics.

\begin{tabular}{|c|c|c|}
\hline Current position & $\mathrm{n}$ & $\%$ \\
\hline EMS manager & 22 & 23.4 \\
\hline EMS physician & $15^{*}$ & 16.0 \\
\hline Paramedic educator & $13^{\dagger}$ & 13.8 \\
\hline Paramedic researcher & 9 & 9.6 \\
\hline EMS regulator & $8^{\ddagger}$ & 8.5 \\
\hline EMS researcher & 6 & 6.4 \\
\hline EMS physician researcher & 7 & 7.4 \\
\hline EMS provider & $5^{\S}$ & 5.3 \\
\hline No response & 9 & 9.6 \\
\hline Primary EMS-related affiliation & $\mathrm{n}$ & $\%$ \\
\hline $\begin{array}{l}\text { EMS service: provincial service (including EMS authority/ } \\
\text { contract administrator) }\end{array}$ & 23 & 24.5 \\
\hline University & 10 & 10.6 \\
\hline Government EMS regulator & 9 & 9.6 \\
\hline Hospital & 9 & 9.6 \\
\hline EMS Medical Control Agency & 7 & 7.4 \\
\hline Other education institution & 5 & 5.3 \\
\hline $\begin{array}{l}\text { EMS service: private sector EMS contractor/service } \\
\text { provider }\end{array}$ & 3 & 3.2 \\
\hline EMS service: Hospital-based & 3 & 3.2 \\
\hline EMS service: other & 3 & 3.2 \\
\hline Regulatory college & 3 & 3.2 \\
\hline Professional association & 2 & 2.1 \\
\hline EMS service: municipal, fire-based & 1 & 1.1 \\
\hline First Response Agency & 1 & 1.1 \\
\hline EMS Communications Centre & 1 & 1.1 \\
\hline Government & 1 & 1.1 \\
\hline Other (retired) & 1 & 1.1 \\
\hline No response & 1 & 1.1 \\
\hline Province & $\mathrm{n}$ & $\%$ \\
\hline Ontario & 25 & 26.6 \\
\hline Nova Scotia & 14 & 14.9 \\
\hline Alberta & 12 & 12.8 \\
\hline British Columbia & 6 & 6.4 \\
\hline Newfoundland and Labrador & 6 & 6.4 \\
\hline New Brunswick & 5 & 5.3 \\
\hline Quebec & 5 & 5.3 \\
\hline Prince Edward Island & 4 & 4.2 \\
\hline Saskatchewan & 3 & 3.2 \\
\hline Manitoba & 2 & 2.1 \\
\hline Yukon & 2 & 2.1 \\
\hline No response & 10 & 10.6 \\
\hline \multicolumn{3}{|c|}{$\begin{array}{l}*=\text { One respondent chose Other and wrote "EMS medical director"; } \\
+=\text { one respondent chose Other and wrote "paramedic training and QA"; } \\
{ }^{+}=\text {two respondents chose Other and wrote "base hospital administrator" and "health } \\
\text { ministry"; } \\
\$=\text { one respondent chose Other and wrote "EMS provider and researcher. }\end{array}$} \\
\hline
\end{tabular}

- Universities should consider EMS providers with graduate training for academic appointments, so they can engage in academic EMS research (\#4). 


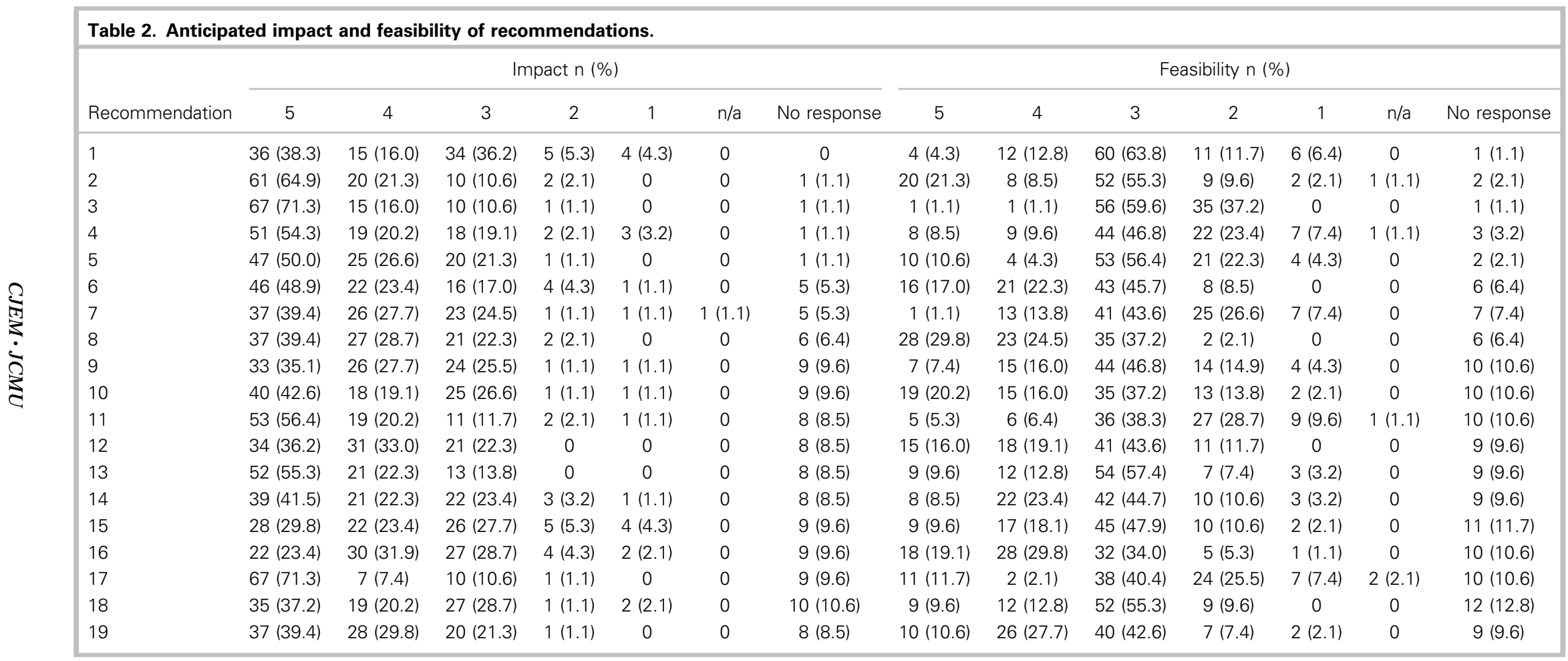


- Create opportunities for EMS providers to work in research positions. Review collective agreements if necessary (\#5).

- Integrate research literacy and research competencies into EMS providers', managers', and EMS physicians' foundational and continuing education (\#6).

- EMS systems administrators should budget for research projects during annual strategic planning (\#11).

- Evidence-based decision-making should be encouraged in EMS systems. If evidence is lacking, further research should be undertaken (\#13).

- EMS data should be linked with hospital and other datasets (\#17).

Four of these recommendations (\#2, 3, 4, and 5) were related to time, opportunities, and funding for EMS research. ${ }^{4}$

There were two recommendations with a median impact score of 4 and median feasibility score of 4 (\#8 and \#16), suggesting that the perceived impact of these recommendations was less than the eight highestimpact recommendations, but that they would be somewhat easier to implement with existing-or only minimal additional-resources.

The remaining nine recommendations also had a median impact score of 4 , but a median feasibility score of 3, suggesting that participants felt these recommendations could make a difference for EMS, but they would require some additional effort or resources to implement. Four of these nine recommendations related to the culture of research and collaboration for EMS research (\#1, 9, 10, 14).

\section{Initiatives related to the recommendations and resources required}

In total, the participants reported 70 unique ongoing or established initiatives relevant to the research agenda recommendations. A range of 0-9 initiatives was reported per recommendation. The recommendation with the most ongoing initiatives was \#2: Strengthen research partnerships between EMS academic centers, systems, regulators, educators, and national associations. The recommendation with the least ongoing or established initiatives reported was \#16: Highlight EMS research in special issues or sections of the Canadian Fournal of Emergency Medicine.

Respondents also identified a total of 71 distinct resources they felt to be required to implement the research agenda recommendations, with a range of 1-11 resources required per recommendation. The recommendations with the fewest resources deemed to be required were \#13: Evidence-based decision-making should be encouraged in EMS systems. If evidence is lacking, further research should be undertaken; and \#18: Create a national EMS data dictionary of operational and clinical terms, each with one resource identified. The recommendation with the most resources deemed to be required was \#19: The EMS Research Agenda needs to be viewed as an ongoing project. An implementation, evaluation, and renewal plan should be designed and this process should include mapping gaps in EMS research.

The initiatives and resources required for each recommendation are listed in Appendix B.

\section{DISCUSSION}

This implementation study provides an understanding of what has already been accomplished and what remains needed for the recommendations of the Canadian National EMS Research Agenda to be implemented. Prior to this investigation, which recommendations were perceived to have the greatest impact and their ease of implementation were unknown. Participants indicated that they felt all of the recommendations could make a difference and were possible to implement. Many ongoing and planned initiatives related to the recommendations were also identified.

A finding of this work of relevance to policymakers is that none of the recommendations had a median feasibility score of 5 , and only two recommendations attained a median feasibility score of 4 . This suggests that a full implementation of the Canadian EMS Research Agenda cannot be achieved without additional resources.

Arguably, one of the most important benefits of a research agenda is the discussion and engagement that must occur among stakeholders for such a report to be produced. The results of our impact and feasibility study are anticipated to further these local and national discussions, by providing guidelines on which recommendations for change are perceived to have the highest impact and be the most feasible and which require targeted investment in resources and leadership. Participants of the Canadian EMS Research Agenda clearly indicated that the findings of the agenda needed to be acted upon, and not simply reported. ${ }^{5}$ Our hope is that by studying the anticipated impact and feasibility of implementing 
these previously generated recommendations, our findings will facilitate EMS research and strategic planning.

A limitation of this study is that a selection bias may have arisen from our sampling strategy. The sample consisted of individuals who were generally interested in or invested in EMS research. This may have overestimated the impact and underestimated the feasibility of various recommendations compared to a sample randomly selected from all EMS personnel across Canada. While we attempted to recruit participants from a diverse range of EMS services and locations, some were likely not represented. Our results represent the responses of participants and their perceptions regarding the anticipated impact and feasibility of implementing each of the recommendations. Prospective evaluation would be required to determine the actual implementation impact and feasibility. There may be other ongoing initiatives that relate to the EMS research agenda recommendations that were not captured, and, similarly, resources may exist that are necessary for implementation that we failed to identify. The distribution of respondents did not mirror the population density, and, as such, impact or implementation issues that are provincedependant may not have been appropriately identified. Finally, although our results pertain to the Canadian setting, they may lack generalizability to other nations.

\section{CONCLUSIONS}

For most of the 12 previously generated recommendations of the Canadian National EMS Research Agenda, the anticipated impact is deemed to be higher than the feasibility to implement by EMS research stakeholders. There are ongoing or planned initiatives pertaining to all recommendations, except one; however, all require additional resources to implement. The implementation of the National EMS Research Agenda recommendations is anticipated to make important improvements in EMS research but perceived to require dedication, resources, and collaboration across planned and ongoing initiatives to achieve. Dedicated resources are required to thoroughly implement the Canadian National EMS Research Agenda.

Author contributions: JLJ, IEB, and BLB developed the research concept and plan. JLJ obtained research ethics approval. JLJ, IEB, and BLB obtained funding. JLJ, IEB, BLB, and RB recruited and enrolled participants. All authors contributed substantially to the design and methodology of this study and to the writing and critical editing of this manuscript, and intend to remain significantly involved in the study until completion. All authors have read and approved the final manuscript.

Acknowledgements: The authors wish to thank all who completed the study survey.

Competing interests: None declared.

\section{SUPPLEMENTARY MATERIAL}

To view supplementary material for this article, please visit http://dx.doi.org/10.1017/cem.2015.29

\section{REFERENCES}

1. Sayre MR, White LJ, Brown LH, et al. National EMS research agenda. Prehosp Emerg Care 2002;6(3 Suppl): S1-43.

2. Centre for Prehospital Research, University of Limerick. A national prehospital research strategy; 2008. Available at: http://www2.ul.ie/pdf/358997750.pdf.

3. Tippett V, Clark M, Woods S, et al. Towards a national research agenda for the ambulance and pre-hospital sector in Australia. FEPHC 2003;1:1-2.

4. Jensen JL, Bigham BL, Blanchard IE, et al. The Canadian national EMS research agenda: a mixed methods consensus study. CFEM 2013;15(2):73-82.

5. Dainty KN, Jensen JL, Bigham BL, et al. Developing a Canadian EMS research agenda: a baseline study of stakeholder opinions. Prehosp Emerg Care 2012;16(1):184-5.

6. Foltin GL, Dayan P, Tunik M, et al. Priorities for pediatric prehospital research. Pediatr Emerg Care 2010;26(10): 773-7.

7. Patterson DG, Skillman SM. A national agenda for community paramedicine research. Seattle, WA: WWAMI Rural Health Research Centre, University of Washington; 2013.

8. Blanchard IE, Brown R, Jensen JL, et al, and the Canadian EMS Research Agenda Investigator Team. Barriers, facilitators, recommendations, and priorities for EMS research: a scoping review of research agendas [abstract]. Prebosp Emerg Care 2013;17(1):121.

9. Sayre MR, White LJ, Brown LH, et al. The national EMS research strategic plan. Prehosp Emerg Care 2005;9(3):255-66.

10. Sayre MR, White LJ, Brown LH, et al. National EMS research agenda: proceedings of the implementation symposium. Acad Emerg Med 2003;10(10):1100-8.

11. Graham ID, Logan J, Harrison MB, et al. Lost in knowledge translation: time for a map? 7 Contin Educ Health Prof 2006;26(1):13-24.

12. Jensen JL, Blanchard IE, Bigham BL, et al. Methodology for the development of a Canadian national EMS research agenda. BMC Emerg Med 2011;11:15.

13. Heckathorn DD. Respondent-driven sampling: a new approach to the study of hidden populations. Soc Probl 1997;44(2):174-99. 